\title{
Severe microcephaly with normal intellectual development: the Nijmegen breakage syndrome
}

Department of Clinical Genetics,

Addenbrooke's NHS

Trust, Cambridge and

Department of

Pathology, University

of Cambridge

A J Green

J R W Yates

Department of Cancer Studies, University of Birmingham Medical

School

A M R Taylor

P Biggs

G M McGuire

C M McConville

Department of

Cytogenetics,

Addenbrooke's NHS

Trust, Cambridge

C J Billing

Department of

Paediatrics,

Addenbrooke's NHS

Trust, Cambridge

N D Barnes

Correspondence to:

Dr Andrew Green,

Department of Clinica

Genetics, Box 134,

Addenbrooke's NHS Trust,

Cambridge CB2 2QQ.

Accepted 7 June 1995

\author{
A J Green, J R W Yates, A M R Taylor, P Biggs, G M McGuire, C M McConville, \\ C J Billing, N D Barnes
}

\begin{abstract}
$A$ brother and sister are described with severe microcephaly of prenatal onset, normal intellectual and motor development, chromosomal breakage and cellular immunodeficiency, which is characteristic of the autosomal recessive condition, Nijmegen breakage syndrome.

The proband was a girl who presented at 15 months, with normal developmental milestones and an extremely small head circumference of $36 \mathrm{~cm}$. Twenty per cent of her lymphocytes showed spontaneous translocations involving chromosome 7p13, 7q35, 14q11, and 14q32. The lymphocytes also showed excessive $x$ ray induced chromosome damage. She had $T$ cell lymphopenia, but normal immunoglobulins, and a normal $\alpha$ fetoprotein. A brother was born shortly after her diagnosis was made. He also had extreme microcephaly of $28 \mathrm{~cm}$, with similar spontaneous and $x$ ray induced chromosomal breakage, and $T$ cell lymphopenia. Neither child has clinical evidence of immunodeficiency.
\end{abstract}

To test the hypothesis that Nijmegen breakage syndrome and ataxia telangiectasia are allelic disorders, haplotype analysis was carried out in the family using DNA markers spanning the AT locus on chromosome 11q22. The affected boy had a different haplotype from his affected sister. Thus in this family, the Nijmegen breakage syndrome is not allelic to the ataxia telangiectasia locus on chromosome $11 \mathrm{q}$, and the two conditions are genetically distinct. The normal intellect in these children raises questions about normal brain development in the presence of severe microcephaly.

(Arch Dis Child 1995; 73: 431-434)

Keywords: Nijmegen breakage syndrome, microcephaly, chromosome breakage, ataxia telangiectasia.

Microcephaly associated with developmental delay is a common presentation in paediatric practice. There are many causes, including perinatal and obstetric insults, chromosomal aneuploidy, and several genetic syndromes. About $50 \%$ of children with unexplained nonsyndromal microcephaly have an autosomal recessive pattern of inheritance for the condition. Most children with microcephaly have serious intellectual impairment, and normal mental development is rare.
Nijmegen breakage syndrome is a recently described condition characterised by microcephaly, immunodeficiency, and typical chromosome breakage involving chromosomes 7 and $14 .^{1}$ It has been suggested that it may be an allelic variant of ataxia telangiectasia, in which there is identical chromosome breakage and immunodeficiency but a distinct clinical presentation. ${ }^{2} 3$ Paradoxically in most cases there has been severe microcephaly but normal intellectual development. We describe a sister and brother with these findings. They had chromosomal breakage characteristic of Nijmegen breakage syndrome and significant $T$ cell lymphopenia but no clinical evidence of immunodeficiency. Haplotype analysis in this family, using DNA markers flanking the ataxia telangiectasia locus on chromosome 11q22, showed that in this family the condition is not an allelic form of ataxia telangiectasia.

\section{Case description and investigations}

A 15 month old girl was referred for assessment because of microcephaly of prenatal onset. She was the second child of healthy unrelated white English parents, the first child being a normal girl of 6 years. The pregnancy was complicated by hypertension and premature labour, and she was born by caesarean section at 36 weeks' gestation, with a weight of $1890 \mathrm{~g}$, and a head circumference well below the third centile at $29 \mathrm{~cm}$. After initial nasogastric feeding she fed well and gained weight.

At presentation, her motor and social development was normal for her age. She had not had any excess of infections, and had received diphtheria, pertussis, tetanus, and live polio vaccines without incident. Her length had followed the 3 rd centile, with her weight slightly below the 3rd centile. Her head circumference was only $36 \mathrm{~cm}$, being on the 50th centile for a term newborn (see fig 1). She was not dysmorphic. Her parents' and sister's head circumferences were normal. Investigations including skull radiography, computed tomography of the brain, blood count, electrolytes, liver enzymes, calcium, phosphate, thyroid function, and TORCH screen were all normal.

Her karyotype was $46, \mathrm{XX}$ in the majority of lymphocytes. Structural rearrangements involving chromosomes 7 and 14 were present in $20 \%$ of cells. The karyotypes in these cells were $46, \mathrm{XX}, \operatorname{inv}(7)(\mathrm{p} 13 ; \mathrm{q} 35), 46, \mathrm{XX}, \mathrm{t}(7 ; 14)$ (q35; $\mathrm{q} 32)$, and $46, \mathrm{XX}, \mathrm{t}(14 ; 14)(\mathrm{q} 11 ; \mathrm{q} 32)$. Studies of her lymphocyte chromosomes by $x$ ray were performed as described. ${ }^{4}$ Compared with normal lymphocytes, there was a marked increase in $x$ ray induced chromosome damage 


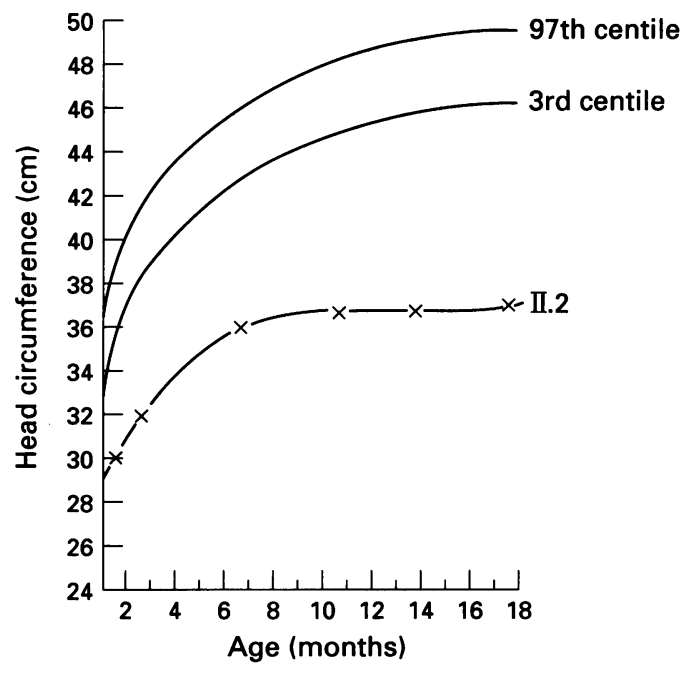

Figure 1 Graph of head circumference ( $\mathrm{cm}$ ) versus age in the proband (II.2), compared with 3rd and 97th centiles.

after exposure to 1 Gray at the G2 stage of the cell cycle (see fig 2 ). The specific spontaneous chromosome rearrangements and irradiation induced chromosome damage were typical of ataxia telangiectasia.

However, microcephaly is not a feature of ataxia telangiectasia, and her concentrations of $\alpha$ fetoprotein were normal. She had no signs of ataxia and no telangiectasia, although this would not be expected at 15 months of age in a child with ataxia telangiectasia. In view of the chromosome breakage, her immune system was assessed. She had low values of T lymphocytes, with a total lymphocyte count of $2.39 \times 10^{9} / 1$, a $T$ cell count of $0.96(40 \%)$, a B cell count of $0.79(33 \%)$, and relatively high natural killer cells of $0.48 \quad(20 \%)$. The CD4/CD8 ratio was normal. There were no clonal rearrangements of her T cell receptor $\alpha$ or $\beta$ genes on Southern blot analysis. She had normal immunoglobulin concentrations, including IgG subsets and IgE, and a normal antibody response to tetanus immunisation. In the light of the severe microcephaly, normal intelligence, $\mathrm{T}$ lymphopenia and chromosome breakage, a diagnosis of Nijmegen breakage syndrome was made.

Her parents' lymphocyte karyotypes, and that of her healthy sister showed neither chromosome 7:14 rearrangements, nor excess

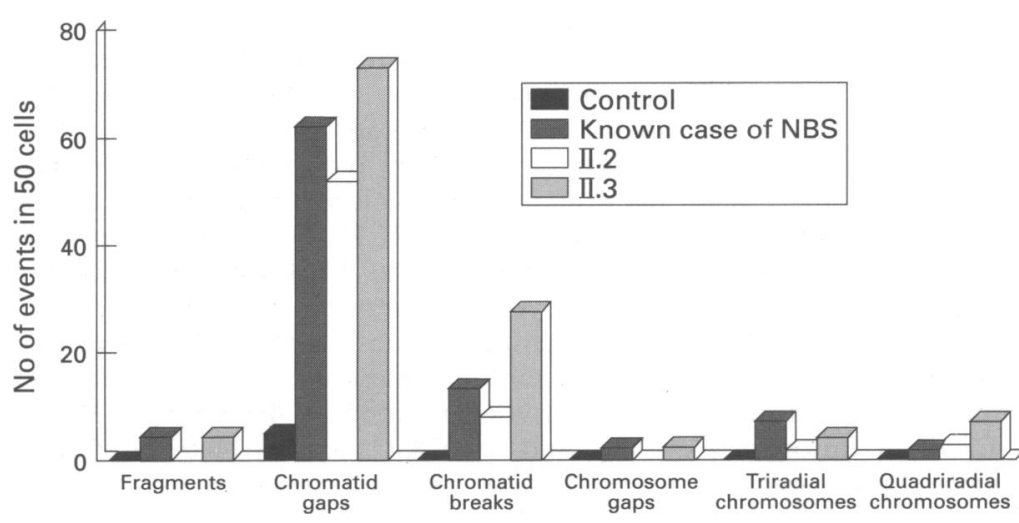

Figure 2 Excess chromosomal breakage in response to 1 Gray $\mathrm{x}$ irradiation at G2 in lymphocytes from both affected children (II.2 and II.3) and a known case of Nijmegen breakage syndrome (NBS; not UK). $x$ ray induced chromosome breakage. A brother was born shortly after the diagnosis was made. He was born at 38 weeks' gestation, with a birth weight of $2560 \mathrm{~g}$. He had severe microcephaly of $28 \mathrm{~cm}$ at birth, T cell lymphopenia, and his lymphocytes showed similar rearrangements of chromosomes 7 and 14 in $20 \%$ of cells. The karyotypes in these cells were 46,XY, inv(7) (p13;q35), 46,XY,t $(7 ; 14)$ (p13; $\mathrm{q} 11), 46, \mathrm{XY}, \mathrm{t}(7 ; 14)(\mathrm{q} 35 ; \mathrm{q} 11)$, and $46, \mathrm{XY}, \mathrm{t}$ $(7 ; 7)(\mathrm{p} 13 ; \mathrm{q} 35)$. His lymphocytes showed excess chromosome breakage in response to $x$ irradiation similar to his sister (see fig 2). A diagnosis of Nijmegen breakage syndrome was also made, consistent with the predicted autosomal recessive inheritance.

On review at age 3, the proband was developmentally normal, with a head circumference of $39.5 \mathrm{~cm}$, with her height on the 3 rd centile, and her weight just below the 3rd centile. She had not had any major infections. Her 14 month old affected brother was bottom shuffling, had a few words, and had not had any major infections. His head circumference was small at $40 \mathrm{~cm}$, with his length and weight on the 10 th centile.

Haplotype analysis was performed in the family, using previously described polymorphic DNA markers flanking the ataxia telangiectasia locus on chromosome 11q22-23 (see fig 3). ${ }^{5}$ If the Nijmegen breakage syndrome were allelic with ataxia telangiectasia, then both affected children should have had identical parental haplotypes in the region of the ataxia telangiectasia locus. However, each affected child had inherited a different paternal haplotype in the region of chromosome 11 q22 to which ataxia telangiectasia maps, between the markers D11S1343 and D11S1897. Thus there was no common combined haplotype between the affected siblings, as they had different copies of their father's ataxia telangiectasia genes on chromosome 11q22. It follows that in this family the Nijmegen breakage syndrome is not allelic to ataxia telangiectasia on chromosome 11q22, contrary to previous suggestions. $^{23}$

\section{Discussion}

Nijmegen breakage syndrome, which has also been called Seemanova's syndrome, is a rare autosomal recessive condition characterised by microcephaly, severe immunodeficiency, and excess chromosome breakage involving chromosomes 7 and 14. Weemaes et al first described the disorder in two affected siblings, the children of consanguineous parents, and named it the Nijmegen breakage syndrome. ${ }^{1}$ Seemanova et al described eight children of Czech origin, all with microcephaly and severe humoral and cellular immunodeficiency. ${ }^{6}$ Three of the Czech children have been shown subsequently to have excess chromosome breakage, and the two conditions appear to be the same entity. ${ }^{2}$ To date, a total of 30 patients with probable Nijmegen breakage syndrome have been described in 21 families, almost all of eastern European origin. ${ }^{7}$

Seventeen confirmed cases, all with 7:14 


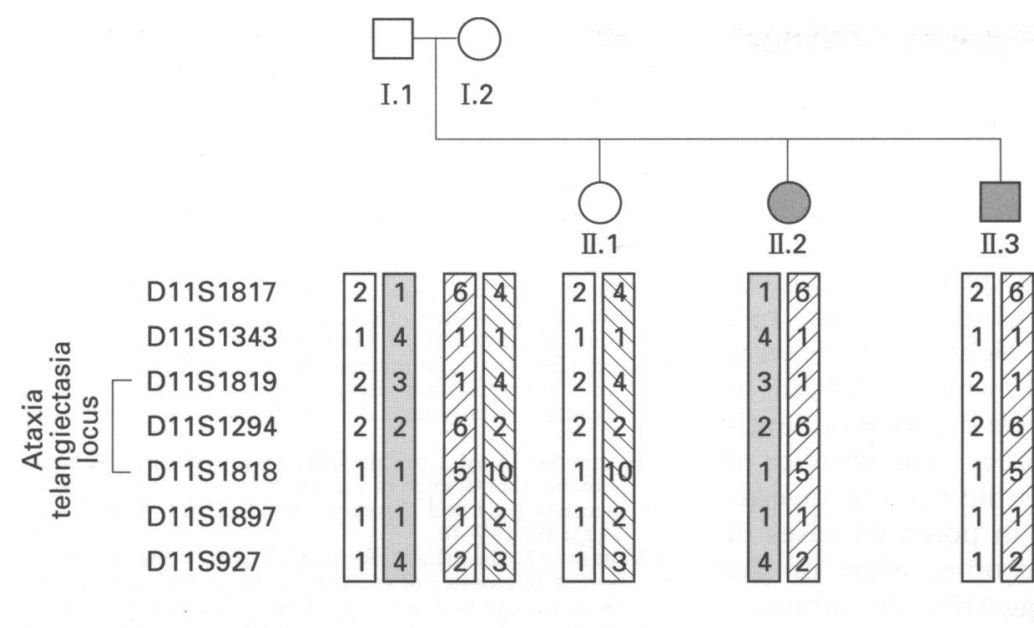

Haplotype
A B C D A D

B C

family was reported as normal. Two Pakistani girls, the offspring of a first cousin marriage, were described with microcephaly, areas of skin depigmentation, 'bird-like' facies, and normal intelligence. One sister had acute lymphoblastic leukaemia, but showed no spontaneous or induced chromosomal breakage. ${ }^{15}$ These cases may reflect genotypic or phenotypic heterogeneity within a broad clinical classification of Nijmegen breakage syndrome.

It has been suggested that the condition may be allelic with ataxia telangiectasia, a DNA repair disorder which has identical cytogenetic findings and similar immunodeficiency but distinct clinical findings. ${ }^{2}$ Jaspers et al described two complementation groups of Nijmegen breakage syndrome, $V_{1}$ and $V_{2}$, which did not complement any of the known ataxia telangiectasia groups. ${ }^{16}$ Those families in the $V_{2}$ group appeared to have congenital abnormalities not seen in the $V_{1}$ group. Curry et al described Mexican twin sisters with microcephaly, mental retardation, immunodeficiency, ataxia, scleral telangiectasia, a raised $\alpha$ fetoprotein, and chromosomal breakage involving chromosomes 7 and $14 .^{3}$ These are features of ataxia telangiectasia and Nijmegen breakage syndrome, and the findings suggest that there is clinical overlap between the two conditions. This overlap condition was named $\mathrm{AT}_{\text {Fresno. }}$. Complementation analysis showed these sisters to fall into the $V_{1}$ complementation group. ${ }^{16}$ Haplotype analysis in this family supported linkage at $A T_{\text {Fresno }}$ to DNA markers in the region of the AT locus on chromosome $11 \mathrm{q} 22.17$

In almost all families with ataxia telangiectasia, the condition is linked to markers on chromosome 11q22.18 Occasional families may not show linkage to chromosome $11 \mathrm{q} 22 .{ }^{17} \mathrm{We}$ therefore analysed the family we describe for linkage to DNA markers on chromosome $11 \mathrm{q} 22$ and were able to exclude this locus as a cause of the condition. The Nijmegen breakage syndrome is thus not allelic with ataxia telangiectasia, at least in this family. These data do not exclude the possibility of genetic heterogeneity in Nijmegen breakage syndrome, with some other cases linked to chromosome 11q22.

Haplotype studies and complementation studies have been performed in Nijmegen breakage syndrome families with the $\mathrm{V}_{2}$ complementation group. These have shown that the condition is not linked to the ataxia telangiectasia gene region on chromosome $11 \mathrm{q} 22 .{ }^{17}$ Children in the $V_{2}$ group show various congenital anomalies not seen in the $V_{1}$ group. It is not clear at present whether there is a consistent relationship between complementation group and the level of congenital anomalies in Nijmegen breakage syndrome (C M R Weemaes, personal communication). If this family is more likely to be in the $\mathrm{V}_{1}$ complementation group on the basis of the absence of any associated anomalies, then haplotype analysis would indicate that the $\mathrm{V}_{1}$ complementation group of Nijmegen breakage syndrome is also not linked to the ataxia telangiectasia gene region on chromosome $11 \mathrm{q} 22$. members, all of whom had microcep was described 14 Chromosomal analysis in this 
A further concern is the degree of immunodeficiency in the children we describe, neither of whom has had serious infection. Live vaccines have been avoided, however the proband had received live polio vaccine before diagnosis with no sequelae. Death from infection occurred in three of the other confirmed cases. Of 30 definite or probable children with Nijmegen breakage syndrome, nine had developed a malignancy, eight of which were lymphomas. ${ }^{7}$ This is a risk, which is difficult to quantify, for the children we describe of developing a lymphoid malignancy. The absence of serious infection indicates the need to investigate the immune system in potential cases of Nijmegen breakage syndrome, even in the absence of a history suggestive of immunodeficiency.

The striking clinical feature of the condition is the preservation of intellectual development despite severe microcephaly. This is in contrast to the mental impairment commonly seen in isolated or autosomal recessive non-syndromal microcephaly. It is difficult to provide a biological explanation for normal functional brain development without normal brain growth. Discovery of the gene responsible for Nijmegen breakage syndrome may give a clue to such development. The finding of normal intelligence in the presence of profound microcephaly should prompt close analysis of the karyotype and assessment of the immune system.

Nijmegen breakage syndrome is a rare cause of microcephaly, and the diagnosis is important because of the immune deficit, and also for the recurrence risk of an autosomal recessive disorder. The condition does not appear to be allelic with ataxia telangiectasia. The marked discrepancy between profound microcephaly and normal intellectual development is characteristic.

\section{Addendum}

The gene for ataxia telangiectasia on chromosome 11q22 has recently been published, and encodes a protein resembling phosphatidylinositol $-3^{\prime}$ kinases involved in signal transduction, meiotic recombination, and cell cycle control (Savitsky et al, Science 1995; 268: 1749-53).

1 Weemaes CMR, Hustinx TWJ, Scheres JMJ, van Munster PJJ, Bakkeren JAJM, Taalman RDFM. A new chromosomal instability disorder: the Nijmegen breakage syndrome. Acta Paediatr Scand 1981; 70: 557-64.

2 Taalman RDFM, Hustinx TWJ, Weemaes CMR, et al. Further delineation of the Nijmegen breakage syndrome. Firther delineation of the Nijmege

3 Curry CJR, Tsai J, Hutchinson HT, et al. AT Fresno: a phenotype linking ataxia-telangiectasia with the Nijmegen breakage syndrome. Am f Hum Genet 1989; 45: $270-5$.

4 Hernandez D, McConville CM, Stacey M, et al. A family showing no evidence of linkage between the ataxia telangiectasia gene and chromosome 11q22-23. F Med Genet 1993; 30: 135-40.

5 Vanagaite L, Savitsky K, Rotman G, et al. Physical localization of microsatellite markers at the ataxia-telangiectasia locus at 11q22-23. Genomics 1994; 22: 231-3.

6 Seemanova E, Passarge E, Beneskova D, Houstek J, Kasai P, Sevcikova M. Familial microcephaly with norma intelligence, immunodeficiency, and risk for lymphoreticular malignancies: a new autosomal recessive disorder. $A m \mathcal{F}$ Med Genet 1985; 20: 639-48.

7 Weemaes CMR, Smeets DFCM, van der Burgt CJAM Nijmegen breakage syndrome: a progress report. Int $\dot{f}$ Nijmegen breakage syndrom:

8 Barbi G, Scheres JM, Schindler D, et al. Chromosome instability and X-ray hypersensitivity in a microcephalic instability and X-ray hypersensitivity in a microcephalic and grow 5 .

9 Conley ME, Spinner NB, Emanuel BS, Nowell PC, Nichols WW. A chromosomal breakage syndrome with profound immunodeficiency. Blood 1986; 67: 1251-6.

10 Stoppa-Lyonnet D, Girault D, LeDeist F, Aurias A. Unusual $T$ cell clones in a patient with Nijmegen breakage syndrome. $\mathcal{F}$ Med Genet 1992; 29: 136-7.

11 Wegner RD, Metzger M, Hanefeld F, et al. A new chromosomal instability disorder confirmed by complementation studies. Clin Genet 1988; 33: 20-32.

12 Jaspers NGJ, Taalman RDFM, Baan C. Patients with an inherited syndrome characterised by immunodeficiency, microcephaly, and chromosomal instability: genetic relationship to ataxia telangiectasia. Am $\mathcal{F} \mathrm{Hum}$ Genet 1988; 42: 66-73.

13 Maraschio P, Peretti D, Lambiase S, et al. A new chromosomal instability disorder. Clin Genet 1986; 30: 353-65.

14 Teebi AS, Al-Awadi SA, White AG. Autosomal recessive nonsyndromal microcephaly with normal intelligence. Am $\mathcal{f}$ Med Genet 1987; 26: 355-9.

15 Heney D, Mueller R, Turner G, et al. Familial microcephaly with normal intelligence in a patient with acute lymphoblastic leukemia. Cancer 1992; 69: 962-5.

16 Jaspers NGJ, Gatti RA, Baan C, Linssen PCML, Bootsma D. Genetic complementation analysis of ataxia telangiectasia and Nijmegen breakage syndrome: a survey of 50 patients. Cytogenet Cell Genet 1988; 49: 259-63.

17 Gatti RA, Lange E, Rotman G, et al. Genetic haplotyping of ataxia-telangiectasia families localises the major gene to an $\sim 850 \mathrm{~kb}$ region on chromosome $11 \mathrm{q} 23.1$. Int $f$ Radia Biol 1994; 66: S57-62.

18 Foroud $\mathrm{T}$, Wei S, Ziv Y, et al. Localization of an ataxiatelangiectasia locus to a 3-cM interval on chromosome consortium [see comments]. Am ₹ Hum Genet 1991; 49: 1263-79. 